\title{
Antoni Bordoy Fernández, Enseñar filosofía en los albores de la universidad (1200-1240). Estudio histórico acompañado del acceso de los filósofos a las siete artes liberales, Madrid, Sindéresis, 2018, 348 pp., ISBN: 9788416262533 . Cloth $€ 20$
}

\author{
Reseñado por ENCARNACIÓN RUIZ CALLEJÓN \\ Universidad de Granada, ES \\ ruizencarnacion@ugr.es
}

El libro objeto de esta reseña, dividido en cuatro capítulos o bloques, consiste en primer lugar, en un estudio sobre el proceso de creación y constitución de la universidad medieval, la relación en esta de la filosofía con las artes liberales y la transformación de la filosofía de disciplina a ciencia en el periodo entre 1200 a 1240, tomando todo ello como campo de estudio la Universidad de París. En segundo lugar, se lleva a cabo un análisis y la correspondiente traducción de una guía de esta universidad escrita entre 1230 y 1240: el texto anónimo de un Maestro de artes de París Acceso de los filósofos a las siete artes libe-rales.

La primera parte del libro consta de tres capítulos: el origen de la universidad me- dieval, la nueva institución especializada en el nivel más alto de la educación formal; un análisis del origen, estructura y conflictos de la Universidad de París, dedicada a los estudios de artes liberales y teología y con un especial protagonismo en los debates intelectuales que interesan en la época, y un capítulo final sobre las artes liberales y la filosofía con una retrospectiva de la educación que se remonta a Grecia y Roma. El autor desmonta dos posiciones sobre el origen de la universidad medieval: una mítica que lo sitúa en el mundo islámico, y otra que presenta la universidad como un producto planificado que evoluciona desde las escuelas palatinas, las catedralicias y los estudios generales. Sin embargo, es el resultado de una larga y compleja transformación de las necesidades y conflictos de un gremio. En ese proceso jugó un papel importante la Orden de San Benito al tener encomendada la organización educativa, por incluir en su regla la función escolar, y porque con esta Orden se abre paso la convicción de que la decadencia monástica se debía a la falta de textos. Esto hará que el scriptorium se convierta en una pieza fundamental y que el modelo educativo se centre en el texto. La reforma cluniacense de la Orden puso en marcha un nuevo sistema educativo centrado en la conservación y transferencia del saber antiguo emergiendo así un nuevo poder de la Iglesia basado en el control de la educación. A finales del X y primeros del XI se produce la translatio studiorum hacia Occidente y ciudades como Toledo, Montecasino y Salerno serán centros de traducción. Pronto surge la necesidad de centros que preparen al alumnado para acceder a la formación superior, y de regular el funcionamiento y la diferencia entre colegios y estudios generales determinando: la formación que debía tener un maestro, cómo acreditar los conocimientos y cómo otorgar títulos.

La importancia de la Universidad de París contrasta con la escasez de información sobre sus orígenes. Se distinguen dos épocas en su configuración: una primera de 
formación y consolidación como institución (desde su origen hasta la década de 1250) en la que las traducciones que se utilizan son todavía las del siglo XII y la filosofía es aún una disciplina. Desde 1250 pasan a primer plano las ideas y posiciones intelectuales: tenemos a los grandes autores y también las grandes condenas a la filosofía. Los maestros de artes, aún no habiendo pasado a la historia, tuvieron una gran importancia en la configuración de la enseñanza de la filosofía. La constitución completa de la Universidad como institución plena abarca casi un siglo, si bien desde finales del XII y principios del XIII hay un sentimiento de pertenencia a una institución, sobre todo en la Facultad de Artes, la primera que tuvo entidad propia y que, además, era paso obligado para todo estudiante. Se constata una fluctuación de denominaciones de la Universidad de París a lo largo del siglo XIII, pese a funcionar de facto como tal. Hasta 1245 no tenemos una denominación como Universitas parisiensis, si bien su definición total llegará en el último tercio del XIII, dándose la paradoja de grandes maestros en una institución que todavía no tiene una estructura completamente establecida (p. 44).

El funcionamiento como universidad y el proceso de acreditación legal como tal empiezan a desarrollarse a mediados del XII, siendo la primera legislación al respecto la concesión a la comunidad escolar por parte de Inocencio III del derecho a defenderse respecto a las autoridades. El proceso completo concluirá en 1274, año en el que la Facultad de medicina obtiene la licencia. Los orígenes de la Universidad de París y su importancia dependen además de la existencia de una larga tradición de escuelas en París, primero romanas y luego de implantación cristiana, de una educación presencial con una rara dotación de textos, de la existencia continua de docentes de prestigio y de la afluencia de alumnos, muchos de ellos luego personalidades relevantes, lo cual redundará en el prestigio de la institución de formación. Pedro Abelardo impulsó una formación no solo teológica para el clero, sino también en artes liberales. Esto motivó, a su vez, la afluencia de laicos interesados en adquirir una formación de calidad. El resultado fue una proliferación de alumnos laicos que quedaban fuera de la jurisdicción de la Iglesia, regida por su propio derecho (Decreto Graciano, s. XII). Para paliar esta situación, Alejandro III sanciona en el Concilio de Letrán (1179) lo que era ya una práctica: el Canciller del Capítulo catedralicio de Notre Dame otorga la licencia para ser docente. Se establece que este derecho no puede venderse, que se adquiere demostrando los conocimientos y habilidades para ello, y que no puede negarse a quien los demuestre. Pese a la unificación y la institucionalización que se lograba con este sistema, la concentración del poder en una sola persona perteneciente a un ámbito del saber concreto, la teología, resultó negativa: podía conceder licencias, pero también excomulgar y juzgar en lo civil y lo criminal. Los abusos cometidos contra la comunidad educativa hicieron que Inocencio III promulgase una legislación que puso las bases para la existencia de una corporación o entidad legal que sería la universidad de París, pero a la que todavía le faltaría su carta magna y sus estatutos. La constitución como universitas data de 1208/9: Inocencio III insta a los maestros de teología, leyes y artes liberales a prestar juramento a los reglamentos de la institución, no al Canciller, y capacita a la corporación para regularse y defenderse ante los abusos del Canciller. Se analiza también la estructura y funcionamiento del grado en artes liberales: el proceso de 
admisión, las características de los distintos niveles, la metodología de clase, la tipología y contenido de los cursos y el tipo de examen para obtener el título, un aspecto este último que pone de manifiesto, frente a los tópicos de la Edad media filosófica, la importancia de la capacidad argumentativa y la exposición del propio planteamiento. Se especifican los conocimientos previos requeridos para el ingreso a los superiores, la edad de acceso, las vicisitudes en la implantación de la licencia, la competitividad entre los agentes primeramente autorizados para concederla, la divergencia entre las pruebas para obtenerla y las condiciones para obtenerla. Se explica la división del año académico universitario, la metodología de enseñanza, la didáctica utilizada, las lecciones ordinarias y extraordinarias junto con la importancia de estas últimas, los horarios, la evolución del espacio de impartición de las clases y la evolución de los contenidos. Todos estos datos ofrecen una imagen muy precisa de la institución, su evolución y la formación obtenida en ella.

El capítulo tercero de esta primera parte aborda la evolución de la división de los saberes y, especialmente, el lugar de la filosofía en la misma remontándose hasta el mundo clásico en donde la filosofía ocupa el lugar más importante y se empiezan a crear las artes liberales. Dos formas de entender estas marcarán la tradición occidental: una, de corte utilitario, les confiere un valor extrínseco (en la línea de los sofistas y luego Cicerón) como medio para otra cosa; otra -de la mano de la filosofía- abunda es su utilidad interna, y es propia de la tradición platónico-aristotélica. La segunda etapa está vinculada al cristianismo y a su lucha contra el paganismo donde, a juicio del autor, la filosofía desapareceríay sus contenidos los asumen las artes liberales y la teología (p. 77). En la tercera etapa la filosofía se independiza de las artes liberales. La afirmación sobre la desaparición de la filosofía se matiza en la página 86, si bien la actitud hostil del cristianismo sería la causa, a juicio del autor, de que las artes liberales y la filosofía «ya nunca más se pudiesen recuperar en la forma antigua». La recuperación de la filosofía, junto con una clarificación de su relación con las artes liberales, tiene lugar, según el autor, a partir de Boecio y Casiodoro y entre los siglos $\mathrm{V}$ al XI. La translatio studiorum va a dar lugar a dos tradiciones a la hora de entender la filosofía y las artes liberales: una latina representada por Hugo de San Víctor, y otra representada por Domingo Gundisalvo que se nutre de la tradición islámica (especialmente de Alfarabi y Avicena). Con ello se recuperaría la noción aristotélica de una filosofía primera, que aquí incluye el conocimiento de Dios, y la filosofía pasa a concebirse no como una disciplina, sino como una ciencia.

La segunda parte del libro, la más amplia, consiste en un estudio de la obra que se traduce: Acceso de los filósofos a las siete artes liberales. Se analiza el contexto preciso en el que se escribe; la concepción que hay en la época sobre libertad y censura y las regulaciones de 1210 y 1215; las fuentes disponibles en el periodo y las obras de referencia, directa o indirecta, de las que se nutre la guía. El aspecto que queda más desdibujado, si bien no es el objeto de estudio primero del libro, es la contribución de los autores judíos y del hebreo como lengua de transmisión. Por otro lado, la expresión «categorías religiosas islamistas» (p.114) resulta extraña a la época; también cabría precisar el concepto de fe en el caso del islam al ser distinto al del cristianismo. Cabe destacar la pertinente aclaración de la nota 189 (p. 114) que indica en qué sentido ha de entenderse el tradicional papel 
asignado a los autores árabes como transmisores. En cuanto a los medios de control y censura, se detallan las diferentes categorías (de libros, de ideas, sobre personas) y subcategorías (quema de libros, confiscaciones, condena o prohibición, limitación de uso, censura praevia, limitación de la libertad de enseñanza, censuras doctrinales, imposición de doctrinas, procesos y sanciones, intimidación, disciplina de las relaciones entre personas). No se excluye la existencia de lecciones privadas y clandestinas y se contempla lo que algunos autores han denominado «herejía académica» (p. 113).

Los autores y textos de referencia indirecta del Acceso serían: Alfarabi (Catálogo de las ciencias), el corpus aristotélico que se maneja en la época, Isidoro de Sevilla (Etimologías), el Libro de las definiciones del médico y filósofo neoplatónico judío Isaac Israeli, dos textos de Domingo Gundisalvo (Las divisiones de la filosofía y Sobre las ciencias), el Pseudo Dioniso Areopagita (La jerarquía celeste), Sobre la esfera del mundo de Juan Sacrobosco, escrito a principios de la década en la que se sitúa el Acceso y en la que Sacrobosco es docente en París. Respecto a los autores y textos que son referencias fundamentales, hay varias obras de Boecio aparte de La consolación de la filosofía (Aritmética o Sobre el fundamento de la aritmética, Música o Sobre el fundamento de la música); los Elementos de Euclides, el Almagesto de Ptolomeo, Nupcias de Mercurio y Filología, de Marciano Capela, el Timeo y la traducción y comentario de Calcidio, Retórica a Herenio del pseudo Cicerón, y Comentarios a la Retórica de Cicerón de Mario Victorino. Cada una de estas referencias contiene una presentación tanto del autor como de la obra u obras en cuestión.

La tercera parte corresponde a la traducción del Acceso de los filósofos a las siete artes liberales. La traducción va precedida de un análisis sobre los orígenes del texto y un esquema de su estructura. Se explicitan los principios metodológicos adoptados para la traducción, la procedencia y adecuación del título, los manuscritos y la edición crítica tomada como referencia: la de 1988 de Claude Lafleur, por ser la más completa.

El Acceso es una guía para los estudiantes como introducción a los cursos datada entre 1230 y 1240 . No hay registros ni regulaciones por las que podamos saber cuándo y cómo se utilizan estas guías, pero hay consenso entre los especialistas en que se relacionaban con la lección inaugural que el maestro de artes o de teología impartía antes de las lecciones ordinarias de los cursos. A diferencia de las lecciones, los cursos específicos se sitúan en el tramo menos importante del año académico, lo cual dejaba sin embargo al docente más libertad para configurar los contenidos. El texto habría sido redactado tras la regulación de 1231 por la bula de Gregorio IX (Parens scientiarum). Las consecuencias, interpretación, intencionalidad y relación con el resto de regulaciones se discuten en profundidad, especialmente respecto a los libros de Aristóteles de filosofía natural y se dibuja un panorama complejo más allá del tradicional debate de ideas. La bula Parens scientiarum continuaba con las prohibiciones de 1210 y 1215 respecto a la filosofía natural de Aristóteles pero limitaba la prohibición, pues regía hasta que los textos en conflicto fuesen purgados por una comisión creada para ello. Bordoy expone los interrogantes sobre el propósito y funcionamiento efectivo de esta comisión. La guía se escribió, pues, en un contexto en el que se pretende regular el acceso a las fuentes, es necesario definir la 
compatibilidad con el paradigma cristiano, pero se constata cierta relajación respecto a los transgresores a la vez que van cobrando autonomía los maestros de artes para definir los planes de estudio. Hay además escasa información sobre la Universidad de París en esa década concreta.

El Acceso es una de las guías más amplias de las que disponemos. Está concebida para introducir al alumnado en los estudios de artes liberales y filosofía. Responde a un estilo directo que sigue la metodología típica de la época: el desarrollo de un tema atendiendo a los cuatro tipos de causas según Aristóteles. La filosofía que se contempla corresponde al platonismo. La filosofía se entiende como abstracción o elevación del entendimiento sobre lo sensible y sus consecuencias para la actividad del ser humano. Este aspecto, la abstracción, vincula de forma clara la actividad filosófica a la ciencia. En ese sentido, en el Acceso se muestra esa intención de transformar la filosofía de disciplina a ciencia, es decir, de un tipo de conocimiento útil por lo que se obtiene (la instrucción del entendimiento, crear admiración y reverencia a Dios, instruir respecto al valor de lo verdadero frente a lo temporal), a una ciencia autónoma por sí misma. El contenido del texto se centra no en las artes liberales, sino en la filosofía, que es el conocimiento que se reivindica. Se divide en una parte de presentación de esta (razones para su estudio, definición y partes), cuestiones que plantea el autor del Acceso sobre el cuadrivio, y exposición sobre los contenidos de los cursos: aritmética, música, geometría, astrología, La consolación de la filosofía, Timeo y retórica. La parte más personal sería la dedicada a las cuestiones sobre el cuadrivio, siendo el resto más bien paráfrasis de las obras que se señalan.

La cuarta parte del libro, denominada Anexos, incluye una bibliografía general, un glosario de términos técnicos y un listado de los nombres propios que se mencionan en el libro acompañados de las fechas de referencia de nacimiento y muerte. El glosario es especialmente valioso porque explica el vocabulario técnico utilizado en la guía.

El libro de Antoni Bordoy tiene un indudable valor para la investigación sobre la institución y la docencia en la universidad medieval y para conocer el proceso de institucionalización, profesionalización y bases disciplinares de la filosofía en este periodo. La característica más sobresaliente es la combinación de una investigación a fondo de estas temáticas con la traducción de un texto que las ejemplifica: una guía, un género además poco estudiado. El estilo utilizado es claro y riguroso y la metodología es especialmente destacable porque sin desatender los debates de ideas, ofrece una sólida articulación de muy diversos elementos en juego: legales, administrativos, académicos e históricos. En este sentido, quizá un apartado de conclusiones generales e incluso un pequeño balance al final de cada capítulo habrían sido oportunos. Es innegable la dificultad de llevar a cabo una traducción que contiene numerosas expresiones técnicas y ya en desuso, especialmente en el ámbito de la geometría. Destacan las herramientas que se aportan para facilitar la comprensión: un aparato de notas muy riguroso, minucioso y amplio, así como esquemas e imágenes verdaderamente útiles y clarificadores que, sin duda, ayudan a la lectura de la guía y a la comprensión de su alcance. 